\title{
Foreign Language Education Policy in Ireland: A Discourse-Historical Analysis
}

\author{
Marta Gasiorowska \\ University of Birmingham \\ MAG953@student.bham.ac.uk
}

\begin{abstract}
This paper investigates the effects of contextual change on the body of education policy discourse in Ireland, and specifically on discourse pertaining to foreign language education. Discourse-Historical Analysis of key documents reveals a range of micro-, meso- and macro- factors which have had a direct impact on foreign language education policy discourse over the last decade. The objective of this study is to expose complex discursive strategies and tools which serve to convey the relationship between the micro-, meso- and macro-environmental factors and to investigate the effect of contextual change on the body of foreign language education policies. This will be achieved in two ways; firstly, by deconstructing the relevant documents in order to reveal how concepts, problems, causes, imperatives and inevitabilities are discursively framed; and secondly, by examining intertextual connections between texts which make up the discursive sample. It is anticipated that this paper can serve as a testimony to the value and importance of strengthening education policy analysis for effective future interventions into foreign language education in Ireland.
\end{abstract}

Keywords: Language Education policy, Ireland, Discourse analysis, Multilingualism, Foreign language

\section{Introduction}

For a long time, foreign language education in Ireland has been beset with problems. Absence of a languages-in-education policy has time and time again been identified as one of the most acute and persistent challenges. As early as in 1987 the Curriculum and Examinations Boardthe predecessor of the National Council for Curriculum and Assessment, highlighted an urgent need for a 'coordinated approach to language education' (NCCA, 1987, p. 48 cited in NCCA, 2008 , p. 15). Since, there have been further calls for an integrated foreign language education 
policy and curriculum (NCCA, 2003; Language Policy Division and DES ${ }^{1}$, 2008; NCCA, 2008). And yet, thirty years later, Ireland (and Scotland) are the only countries in Europe where foreign language education is not compulsory. Publication of Languages Connect, Ireland's Strategy for Foreign Languages in Education 2017- 2026 (DES, 2017a) has brought about a renewed interest in the topic of foreign language education. Therefore, the timing appears right to initiate a review of the body of foreign language education policies in Ireland.

This paper contains insights from a contextually-oriented analysis of a sample of texts belonging to the domain of foreign language education in Ireland. The overarching objective of this investigation is to establish in what way contextual change has affected foreign language education policy discourse in Ireland in the last decade. Connected to this are the questions of what discursive features are present in the text sample and how they convey the micro-, miso and macro-environmental factors which affect education policy discourse.

\section{Defining Policy}

Defining what is meant by 'policy' is one of the biggest conceptual problems. Commonly the term is associated with legislative bodies and state institutions, i.e. governments or those endowed with legislative powers. Policies represent their measurable output. The kind of texts that come to mind are regulations, strategies, initiatives, guidelines, programs; it is what we may call a 'big-P Policy' (Evans et al., 2008, cited in Ball, 2017, p. 10). The category also encompasses reports, updates, speeches, guides, manuals- in other words any textual piece which helps to reproduce, reinforce and propagate the policy agenda.

Conceptualisation of policy as discourse, contrary to its conceptualisation as text, rests on the assumption that policies are more than merely authoritative statements which articulate what ought to be done. Policies are discursive spaces saturated with multiple, often contradictory and incoherent ideologies and beliefs of the policymakers and consumers of policies alike (Ball, 1994). As a result, these discursive spaces become sites of struggle over interpretations and subsequently enactment of policies. While conceptualisation of language policy as discourse does take into account social agency and intentionality, discursive reading of policy must necessarily include interpretations which are sensitive to context, time and space in which they were conceived. It is only by attending to the changing language and rhetorical constructions, claims Ball (2017, p. 19), that we can begin to see the ways in which policies have histories and the way that they 'join up' within and across different policy fields. 


\section{Approaches to policy research}

Education policy research stems from the broader field of policy studies. Owing to functionalist underpinnings of the latter, education policy studies tend to operate within a restricted grouping of theory and method (Young, 1999). Traditional approaches accommodate empirical, quantitative research as their primary research tool. On the other hand, critical approaches are founded on the assumption that education policy and planning are ideological processes which contribute to maintaining unequal power relationships between various stakeholders. Practitioners of the critical approach focus on ideological aspects of policies by investigating discursive strategies in which texts construct and sustain power relations or otherwise 'naturalise' the social order and specifically relations of inequality (Fairclough, 2001). Coming to grips with the dynamics of social power and dominance is seen as detrimental for understanding how 'discourses get things done, accomplish real tasks, gather authority' (Said, 1986, p.152). Exposing the politicisation of discourse through critical analysis certainly aids greater understanding and awareness of the ways in which policy discourse frames problems, puts forward possible responses and manufactures consent.

\section{Methodology}

This project employs a Discourse-Historical Approach (DHA)- a methodological approach in qualitative research residing within a wider network of analytical frameworks labelled as Critical Discourse Analysis (CDA). Because DHA supports an operationalisable and yet flexible framework it was possible to adapt and modify an eight-stage discourse-historical research practice formulated by Reisigl and Wodak (2009, p. 96-120) so as to suit the size and scope of this investigation resulting in a three-step analytical procedure. Reisigl and Wodak (p. 96) acknowledge that their 'ideal-typical list' of eight steps is 'best realised in a big interdisciplinary project with enough resources of time, personnel and money.' This is not to say that they are dismissive of small-scale studies where researchers may need to apply a more pared-down version of the framework; on the contrary Reisigl and Wodak (2009, p.96) recognise that the researcher may need to 'make explicit choices when devising one's own project' in order to realise its goals and objectives.

The framework adopted for the purpose of this investigative study included (i) selection and collection of relevant discourse samples, followed by (ii) an investigation of discursive strategies and features, which allowed for (iii) formulation of critique on the basis of 
interpretative analysis of the findings. These three stages broadly correspond with 6 out of 8 steps included in Reisigl and Wodak's procedure. A distinct feature of the latter is its granular structure which in this instance had to be compromised by amalgamating individual stages. Only two steps i.e. carrying out a qualitative pilot analysis and including detailed case studies were specifically omitted from this investigative study. All adaptations to Reisigl and Wodak's procedure were primarily motivated by the modest scale of this project. It is acknowledged that researchers wanting to pursue more extensive and in-depth investigations in this area with the explicit purpose of validating or challenging the present findings will want to deploy a more elaborate methodology.

\section{Discourse sample}

The sample of texts is made up of a variety of official documents issued in the last decade pertaining to modern language education in Ireland. Four texts have been selected for analysis on foot of their perceived importance in shaping the contemporary context of foreign language education, their utility for tracing temporal evolution of foreign language education policy in the last decade and for mapping out the dominant policy orientations.

First, the Final Report on the Modern Languages in the Primary School Initiative (DES, 2012) was included in the sample. This document details the successes and challenges of a government initiative aimed at providing foreign language learning opportunities to fifth and sixth grade primary school pupils. The Report marks the end of a project spanning over a decade. In light of competing priorities such as literacy and numeracy skills emphasised by Literacy and Numeracy for Learning and Life: The National Strategy to Improve Literacy and Numeracy among Children and Young People, 2011-2020 (DES, 2011) the initiative was abruptly abolished in 2012 leading to the commissioning of the Report. The Report has been chosen for analysis for two reasons. First, it acts a temporal marker which signals the end of a long running initiative aimed at promoting foreign language education. Second, considering inherently politicised and value-laden nature of the report as a literary form, the level of transparency and reflectivity with which its authors chose to publicly engage with the successes and pitfalls of the initiative was particularly revealing and therefore relevant to this study.

The second and third documents selected for analysis concern the provision of foreign language education as part of Junior Cycle- a three-year long post-primary programme which concludes with a state examination i.e. the Junior Certificate ${ }^{2}$. The Framework for Junior Cycle (DES, 
2015a) outlines the curriculum and associated assessment arrangements. Accompanying the Framework are detailed specifications (syllabuses) for each subject. Specification for Junior Cycle Modern Foreign Languages (DES, 2015b) has been prescribed for teaching French, German, Italian and Spanish. Its content has been organised around three integrated strands: (i) communicative competence, (ii) language awareness, (iii) socio-cultural knowledge and intercultural awareness with the underlying expectation that these skills and knowledge are developed concurrently over a three-year period. Owing to the fact that combined these two documents constitute the only officially approved by the Department of Education and local school boards set of documents guiding students' learning of foreign languages, it was necessary to reconceptualising these two pieces as discourse and include them in the analysis.

The final document being investigated here is Languages Connect, Ireland's Strategy for Foreign Languages in Education 2017- 2026 (DES, 2017a). The Strategy was conceived following an extensive process of public consultation involving a variety of stakeholders ranging from primary schools, post-primary schools, third level institutions, cultural institutes, business enterprises and individuals. The action plan included in the document aims at: (i) improving language proficiency by creating a more engaging environment, (ii) diversifying and increasing the uptake of languages learned and cultivate the languages of the new Irish, (iii) increasing awareness of the importance of language learning to encourage the wider use of foreign languages, (iv) enhancing employer engagement in the development and use of trade languages. These interconnected goals highlight the wide extent to which the Strategy seeks to engage with the cultural, political and economic contexts in which it was conceived. The document was selected for analysis precisely because of the centrality of context in the process leading to the publication of the Strategy, its planned implementation and in the broader pursuit of its goals.

\section{Analysis and findings}

The text sample was subject to a two-way analysis. First, texts were manually annotated at the word-token level of granularity. No commercially available annotator tool was availed of given compact size of the sample. Second, a discourse-level analysis was carried out identifying a range of discourse cues and techniques all of which were manually annotated for. Subsequently four discursive categories emerged: (1) Diversity, (2) Flexibility, (3) Integration, and (4) Sustainability. An in-depth analysis revealed that although these categories were present across the sample, there were important distinctions and divergences. By using the four categories as 
discursive lenses it was possible to identify the key discursive and contextual differences in individual texts and to trace temporal and conceptual evolution of certain themes, assumptions, concepts and values underpinning the body foreign language education policy discourse.

\subsection{Discourse \#1: Diversity}

\subsubsection{The MLPSI}

One of the principal objectives of the MLPSI was 'to promote diversification in the languages taught at primary level' (DES, 2012, p.6). The need to promote diversification was strongly linked to recommendations which had been made by the Council of Europe. The MLPSI was undoubtedly a step towards the EU aim of 'mother tongue plus two' which had been first agreed at the Barcelona European Council in 2002. The following excerpt from the Final Report on the MLPSI illustrates reflection on the progress made:

Policy developments in the area of early language learning have moved at a much more significant rate in other European countries. Indeed, some countries are now also focussing on language learning at a pre-school level and it is increasingly common for primary education to offer more than one modern language.

(DES, 2012, p. 6)

A form of performative benchmarking has been deployed in order to relate Ireland's progress towards the 'mother tongue plus two' agenda in Ireland and in other EU states. The discursive act of exposing Ireland as 'the only European country where in practice modern languages are not taught as part of its primary curriculum' (DES, 2012, p. 7) is particularly noteworthy. This overt statement reaffirms earlier claims about Ireland's deficient practices. It also rests on the assumption that Ireland is in (in)direct competition with other European nations which implies that every effort should be made to ensure that the country does not lag behind in what is inherently a 'race'. This discursive tactic covertly legitimises the actions undertaken as part of the MLPSI. It is noteworthy that the practice of highlighting own shortcomings is in contrast with a claim advanced by Van Dijk (1993) who claimed that policy makers tend to emphasize positive aspects about themselves while bringing to the fore negative aspects about the others. Here the opposite is the case; negative self-representations have been juxtaposed with positive representation of 'the other' European countries and yet paradoxically this 'reversed' strategy achieves the same objective, that is it mobilises stakeholders' support for the Initiative. 


\subsubsection{Junior Cycle Curriculum}

In principle proliferation of foreign languages on offer to Junior Cycle students is an unambiguously good thing. The attractiveness of the Curriculum appears to be linked not only to the variety of language choices, but also to the very ability to choose which language(s) students themselves wish to take up as part of their schooling. In addition to 'traditional' modern foreign languages the NCCA has also developed a range of short courses in twelve other languages including Chinese, Japanese, Korean, Lithuanian and Polish. The general rationale provided for including these short courses is that they are expected to broaden the learning experiences for students, address their interests and encompass areas of learning not covered by the combination of curricular subjects available in the school'. (DES, 2015a, p.21). However, according the Post-Primary Languages Ireland Annual Report (PPLI, 2018, p. 19) audit results revealed that in practice students' power to choose is significantly curtailed by a variety of external factors i.e. the size of the school (the smaller the school, the less likely it is to provide a wider choice of languages), geographic location (reduced range of foreign languages on offer in the North-West of the country) and school type (fee-paying schools offer the widest range of languages and show the largest uptake). What is more the variety of languages on offer has not in itself been sufficient to influence students' choice in favour of languages other than French, German, Spanish and Italian. It may be speculated that students continue to settle for options which correspond with choices made by their parents, older siblings, peers, without consideration of whether an alternative would actually meet their unique interests and needs better. It would appear that unless complex decision-making processes and patterns underlying students' choices are fully understood, diversity remains a property of the curriculum but only on paper.

\subsubsection{Languages Connect}

In the Strategy diversity comes to the fore in context of coupling of competing goals. Goal 2 sets out the objective of 'diversifying and increasing the uptake of languages learned' while also focusing on "cultivating the languages of the "New Irish"” (DES, 2017a, p. 2). Here, the question of how to diversify and increase the uptake of foreign languages became entangled with a very different question i.e. of how to manage linguistic pluralism of the immigrant population in this country. According to Briscoe et al. (2009), in educational discourses, 'diverse' is often used as a synonym for 'deficient' and often features in texts pertaining to minorities and indigenous populations. Paradoxically, in this context although the notion of deficiency has indeed been linked to the 'indigenous' population of Ireland i.e. native Irish, in 
terms of its population size it is in fact the largest of all the groups living on this island. And yet by juxtaposing deficiencies of the 'native' Irish population against the perceived linguistic wealth of the 'New Irish', the policy makers succeed in constructing a moral framework around the issue of linguistic diversity, which aids their argument in favour of the proposed intervention in foreign language education.

\subsection{Discourse \#2: Flexibility}

\subsubsection{The MLPSI}

Since the 1990s the Council of Europe and the European Commission have broadcast a consistent message advocating multilingual approach to modern language education. Flexibility, understood here as responsiveness to external factors, translates into development of resources and support services devised in order to address the many challenges and demands associated with implementation of the Initiative. According to the Final Report of the Modern Languages in Primary School Initiative, 1998-2012 (Ibid., 2012) the resources and support services which were developed as part of the Initiative collectively count as one the greatest achievements of the MLPSI and represent a systematic and yet flexible response of the DES to the challenges associated with introducing a language reform.

Certainly, system flexibility is a desirable feature of any initiative as it provides the foundations for the implementation of robust programs. However, for the overall system to remain coherent, the Initiative involving at its peak 546 schools would likely have had to be scaled up. The success of scaling up is influenced by both internal and external factors with flexibility being only one prerequisite. Losing out to another Government programme focusing on areas such as the promotion of multiple literacies and early interventions with regards to reading difficulties was almost inevitable given the Government's ongoing commitment to prioritise rising standards of literacy amongst students.

\subsubsection{Junior Cycle Curriculum}

A shift in curriculum reforms characterized by decentralization and flexibility afforded to teachers, principals, students and parents is a fairly recent phenomenon. Prior to the 1990s, education planning was centralized and bureaucratic in character. Nowadays, education policy discourses seem to be guided by the principle of flexibility and autonomy which is afforded to stakeholders at the lowest, local level of the system. The Framework for Junior Cycle (DES, 2015a) and accompanying it Specification for Junior Cycle Modern Foreign Languages 
document (DES, 2015b) are no different. The latter document stipulates that the Framework 'gives schools greater flexibility to design programmes that are suited to the needs of students and to the particular context of the school' (DES, 2015a, p. 7). What is more, discourse on flexibility became intertwined with discourse on equality and right of access. In the Specifications document it is implied that 'within the school's programme, there is sufficient flexibility to cater for the individual learning needs of all students' (DES, 2015a, p. 27). A vision which emerges from the sample is that of an ethical and socially responsible curriculum which is sensitive to the school's local context, students' background, interests and abilities.

A close inspection of the Framework document reveals that the attractiveness of a flexible curriculum endorsed by policymakers is down to the way in which a number of desirable outcomes (e.g. equal treatment) have been framed as the actual effects of the proposed Framework. It would appear that the complexity associated with implementing of detailed processes and procedures required in order to achieve the objectives has been purposefully pushed aside. This tendency to foreground desirable outcomes as the actual effects is also evident in the Specifications document. The consistency with which the argument in favour of a flexible curriculum has been presented across multiple frames legitimises the curriculum in the eyes of stakeholders but also prevents them from forming their own unbiased conclusions about it.

\subsubsection{Languages Connect}

One of the unique aspect of Languages Connect (DES, 2017a) which does not feature in any other discourse sample, is that here discourse on flexibility is bound up with the discursive themes of human capital and economic development. According to the authors of the Strategy, 'the importance of foreign language skills to the economy cannot be overstated' (DES, 2017a, p. 13). Of course, these claims are valid in the sense that knowledge of foreign languages certainly gives an individual a competitive edge in an increasingly multilingual job market (McNaboe et al., 2015; European Commission, 2015). However, the issue lies with the way in which human capital and economic growth have been depicted with the latter is shown as being both dependent on the former, as well as being constitutive of it. According to Schuller (2000, p. 10) 'merely increasing the stock of human capital in any given society will not ensure social or economic progress'. Foreign language competence constitutes only one aspect of the human capital- in itself insufficient to yield economic value stipulated in Languages Connect (Schuller, 2000, p. 13). The Strategy would certainly benefit from at minimum reference to 
other forms of human capital i.e. social and cultural and from a more extensive exploration of the unique Irish context in which these various forms of capital could apparently be realised 'for profit'. Otherwise the human capital argument underpinning the idea of flexible learning remains somewhat a simplistic assumption.

\subsection{Discourse \#3: Integration}

\subsubsection{The MLPSI}

One of the fundamental principles of the MLPSI was provision of an integrated approach to language learning and teaching. In Content and Language Integrated Learning (CLIL), content and communication are thought to be the cornerstones that create the setting for an engaging learning environment with clear linguistic and subject area goals.

In a seminal discussion paper titled Languages in the Post-Primary Curriculum David Little concluded that:

our [Irish] system has remained almost entirely untouched by the upsurge of international interest in CLIL. As a result we have been largely excluded from a growing European movement that offers a number of benefits calculated to support the implementation of European policy in language education, especially teacher and student exchange of various kinds'.

(Little, 2003, p. 34)

This discourse sample is evidently underpinned by the author's desire for Ireland to stay connected with its European counterparts in terms of the country's education and training systems and the pursuit of modernising objectives. Although this objective was shared by those involved in the MLPSI, especially teachers, according to the Report 'most CLIL lessons in the MLPSI context were a mixture of consolidation and new material and may necessarily have been at times uneven in terms of age appropriate curriculum content.' (Ibid., p.17). This highlights a possibility that many teaching practitioners were likely simultaneously learners themselves as they had to figure out a way of adopting and adapting curricular contents to suit their students' need and level. 


\subsubsection{Junior Cycle Curriculum}

The Specification for Junior Cycle Modern Foreign Languages document is organised around three integrated strands: Communicative competence, Language awareness as well as Sociocultural knowledge and Intercultural awareness (DES, 2015b, p. 11). While the learning outcomes for each strand have been detailed separately, it is intended that students' learning is a fully integrated experience. Despite creating an impression of transparency and clarity around the implementation of each strand, rationale for structuring foreign language education in this manner has not been provided. The only justification that is on offer is that ' $[t]$ hey refer to specific domains of language use (public, personal and educational), which are appropriate to the students' age and experience' (Ibid., p.14). This perceived utility, relevance, practicality and students' experiences have been framed as criteria for structuring the proposed learning objectives. However, it does not go unnoticed that these criteria are in themselves so complex that they would certainly warrant a thorough consideration on their own merits and yet no such consideration is afforded to them in the Specification document (DES, 2015b).

\subsubsection{Languages Connect}

The Strategy document states that '[e]ducation is central to all our ambitions as a nation. It supports the development of a strong, growing economy, while also promoting a multicultural and inclusive society' (DES, 2017a, p. 5). This task has been complicated in the last ten years by the wider socio-political and economic changes affecting Ireland. Since the accession of ten new states to the European Union in 2004, Irish policymakers have been grappling with a largely unfamiliar issue of inward migration. The Irish education system, like many other European systems, has found itself at a crossroads. Curriculum designers, policymakers and language planners in particular are facing a monumental task of reconciling the concept of a homogenous nation on one hand, which has for a long time been associated with this country, and on the other the importance of heterogeneity associated with its newest citizens. The Strategy acknowledges that 'immigrant communities are providing Ireland with a rich and diverse source of new languages' and that 'they need to be supported in maintaining their own languages' (DES, 2017a, p. 14). It sets out to 'raise awareness in society at large of the benefits of varied language capacity for intercultural understanding, for positive citizenship.' (DES, 2017a, p. 15). However, while the Strategy overtly promotes inclusion and integration it is not free from contradictions. Covertly the Strategy conveys a notion of a homogeneous state in the sense that multilingualism, or linguistic competence in multiple foreign languages, becomes the quality which binds an increasingly multicultural Irish society together. The point is that 
policies based on integration and inclusion are not in themselves neutral and just like policies of exclusion they are value-laden and problematic.

\subsection{Discourse \#4: Sustainability}

\subsubsection{The MLPSI}

Sustainable education encompasses multiple spheres of human interest and activity with the socio-cultural sphere being one of them. In context of discussion on sustainable foreign language education, of particular interest is the utilisation of two concepts in the Final Report on the MLPSI (DES, 2012a), namely intercultural awareness and cultural awareness. One of the key objectives of the Initiative was 'to develop the child's awareness, appreciation and respect for other cultures, particularly those associated with the target language' (DES, 2012, p.15). The excerpt conveys a message that mastery of grammatical concepts, vocabulary and even oral fluency have ceased to be the ultimate end goals of foreign language learning. A vision of sustainable education which is upheld in the MLPSI is such that knowledge of foreign culture is not merely another target to be reached, a bullet point in a syllabus or a pretext; on the contrary, the proponents of the Initiative recognised that intercultural awareness provides a meaningful context and backdrop against which foreign language education can take place.

\subsubsection{Junior Cycle Curriculum}

Importance of lifelong learning is central to discourse on sustainability. Various European goalsetting exercises over the years have drawn attention to lifelong learning as an integral aspect of sustainable education practices across the EU States (Ball, 2017; Sterling, 2008). Ability to communicate in a language other than one's native language has been called out as one out of the eight key competences for lifelong learning identified by the European Union and European Council (European Council, 2006 quoted in DES, 2015a, p. 4). Given recent socio-economic changes including an unprecedented raise of inward migration, recent financial crisis, labour shortages and in particular insufficient supply of language skills in its domestic workforce, education policy discourse is permeated with claims supporting lifelong learning where it functions almost like an assurance policy. Perhaps the most striking aspect of discourse on lifelong learning is that the concept itself is never quite explained, neither in context of the Junior Cycle Curriculum nor in other discourse samples. The readers are either assumed to know the meaning intended by the policymakers or else it is anticipated that they can infer the meaning from the immediate contextual information. And yet the effect of leaving the concept routinely unstated goes practically unnoticed. This is for two reasons; firstly, as already 
mentioned the fact that educational discourse as a whole appears to be saturated with the idea of lifelog learning masks the concept; secondly, the practice of 'overwording' (Fairclough, 2001), that is frequent listing of the word/phrase, has a naturalising effect meaning that the concept is afforded minimal amount attention, if any at all, by the stakeholders. A thorough analysis of the relationship between linguistic structures and the broader societal context would be required in this instance to reveal the policymakers' definition of lifelong learning.

\subsubsection{Languages Connect}

The notion of sustainability which transpires from Languages Connect is closely linked to economic and financial stability of the country. Explicit statements have been made throughout the document pertaining to the "value that linguistic and cultural diversity delivers to individuals, society and the economy', 'the considerable State investment in the teaching of languages' made to date and the knowledge of foreign languages being 'essential for Ireland's cultural, social and economic welfare' (DES, 2017a). These excerpts reveal that foreign language discourse has become increasingly saturated with concepts and terminology associated with economic policy discourse.

Goal 4 of the Strategy exemplifies the interweaving education and economic elements. The concept of 'knowledge' has become commodified; identities of those endowed with knowledge of foreign languages, and in particular the immigrant population, have been reconstructed and reframed as the 'New Irish'. The Strategy identifies 'a need for ongoing development of language skills' (DES, 2017a, p. 32) and calls for a new kind of 'flexible, lifelong learner who is articulated by policy as human capital in relation to the knowledge economy' (Ball, 2017a, p. 46). The Strategy also signals a shift in the ownership of the education domain with new stakeholders becoming actively involved in policy design and implementation. As new alliances are formed with semi-state bodies, private sectors and lobby groups, education increasingly becomes intertwined with economy and global markets. Owing to these changes it is doubtful whether education policy discourse can continue to be framed via a 'state and public' lens as the case was for decades.

\section{Discussion}

The objective of this investigation is to establish in what way contextual change has affected foreign language education policy discourse in Ireland. Connected to this is the question of how various discursive features convey the relationship between the micro-, miso and macro- 
environmental factors. Owing to context-sensitive nature of this project Discourse-Historical Approach was identified as the most appropriate investigative tool for eliciting answers to those questions. The following discussion has been arranged around three types of contextual policy environment: macro-, micro- and meso-, which stems from Wodak's (2001) multi-level definition of context and Fairclough's (2001) three-dimensional framework for studying discourse.

\subsection{Discourse and Macro-environment}

Discussion concerning the effects of the macro-environment on foreign language education policy is best framed by intertextuality. Intertextuality allows for the content flow from one piece of policy discourse to another to be mapped out both temporarily and spatially. Preceding sections revealed a number of various concepts, values, ideas and linguistic items which are realised differently in samples of foreign language education policy discourse.

One of the most vivid connections between the three discourse samples can be found in the way in which policymakers conceive of and frame the concept of foreign language learning. The MLPSI was largely influenced by the wider European discourses such as Language Education Policy Profile (DES, 2006) emerging in the wake of the Lisbon Strategy. With proficiency in foreign languages rising to the position of 'an important enabler in efforts to translate the aspiration to a knowledge economy into reality' (DES, 2006, p. 37) increasingly discourses associated with the rise of Knowledge-Based-Economy began to gain prominence. It was not until later, when the MLPSI was in its advanced stages, that there occurred a shift from viewing foreign languages merely as another curricular subject to promoting a greater appreciation of the importance of intercultural awareness through modern language learning. On the other hand, cultural awareness was one of the three founding principles underpinning the Specification for Junior Cycle Modern Foreign Languages (DES, 2015b). It is important to acknowledge that the MLPSI was running for over ten years; necessarily it evolved during this period in response to socio-cultural changes which affected Ireland in the first two decades of the twenty-first century. The prominence of language and cultural awareness as vital aspects of foreign language learning cannot escape the readers of Languages Connect (DES, 2017a) either.

Based on the few intertextual connections it is possible to map out changing approach of policymakers to the idea of foreign language learning over the last decade i.e. from where it 
was framed as merely a skill to where it has been recontextualised and where it occupies a prominent position as part of parallel discourses i.e. on lifelong learning. It is therefore argued here that, just as it is impossible to separate policy texts from their contextual environment, neither can discursive power of concepts associated with foreign language learning be disassociated from the web of discourses within which they are embedded and how these discourses connect into a coherent narrative with each other.

\subsection{Discourse and Micro-environment}

Discussion around the micro-context of foreign language policy text and discourse centres around the topic of the actual policy practice. Implementation of each curriculum reform, initiative or, strategy has been dependent, although not exclusively, on its reception and enactment at the micro-level. It is therefore intrinsically linked to social agency and intentionality of policy designers, those targeted by it as well as its opponents. Research shows that indeed macro- policies can only be realised through micro-policies and practices thanks to discursive strategies (Krzyżanowski and Wodak, 2011). A claim is advanced here that observations about shared discursive practices and concepts are nevertheless insufficient to infer conclusions about the actual positioning of the policy authors. This claim is supported by textual evidence in the form of Languages Connect (DES, 2017a), a 'local' Initiative concerning foreign language education. The preceding section revealed that the Strategy signals a departure from the overall strategic aims and policy priorities which have dominated EU language policies on multilingualism for the last two decades and demonstrates how certain discursive practices while shared between the macro- and micro- contexts can potentially distort and obscure the true nature of the relationship between policies belonging within each context.

\subsection{Discourse and Meso-enviroment}

The meso-environment constitutes an interface between the macro- and micro- environments. It is where reforms, initiatives and strategies are transformed into targets, objectives, codes of best practices, standards of excellence. Transformations, refinement, redefinition happening at the discourse level inherently have consequences for our reading and interpretation of policy texts.

Analysis of discourse samples pertaining to foreign language education revealed a number of discursive strategies which convey the relationship between the micro- and macro- 
contexts. The key strategies were: normalisation, naturalisation, overwording and omission. In terms of normalisation, the very concept of what constitutes 'norms' and 'normality' is difficult to define which means that it invites multiple uses and interpretations allowing the policymakers to exploit it for the purpose of conveying their account of 'norms'. Discourse on integration in Languages Connect (DES, 2017a) serves as an example of where appreciation of a value-laden, multifaceted concept of 'multilingualism' has been reduced to merely a norm of 'positive citizenship' (p. 15). Naturalisation and connected with it the practice of overwording both bear similarities to the discursive strategy of normalisation. Concepts such as 'lifelong-learning', 'socio-economic' have become unproblematic co-habitees which feature widely throughout both the Framework for Junior Cycle (DES, 2015a) and Languages Connect (DES, 2017a). The practice of omission, which sits at the opposite end discursive spectrum to overwording, is also noteworthy. Discussed in the section on integration in Junior Cycle Curriculum, the practice of omission also had a distortive effect impacting the policy readers' ability to accurately decipher the relationship between the micro- and macro- contexts.

\section{Conclusion}

The overarching aim of this paper was to present some findings from an analysis of the body of discourse pertaining to foreign language education policy in Ireland. The focus was in particular on discursive practices which are present in the sample and how they lend themselves to the construction of problems, causes, imperatives and inevitabilities. This objective was realised through application of four discursive frames which helped to elicit and analyse an array of discursive strategies present in policy texts. Separate to that, the aim was to uncover the micro-, meso- and macro-environments within which policies are embedded and to reveal their impact on education policy discourse. The results show that across the sample foreign language policy discourse draws extensively on the same ideas, concepts which are reinforced through widespread intertextual connections incorporating textual pieces some of which have been produced a decade apart. However, analysis also revealed a number of discontinuities and transformations signalling evolutionary processes taking place within the body of foreign language educational policy. It is hoped that these findings can inform the work of both researchers and policymakers in developing a long-term effective response to foreign language education needs of the Irish population. 


\section{References}

Ball, S. J. (1998). Big Policies/Small World: An Introduction to International Perspectives in Education Policy'. Comparative Education, 34: 119-130.

Ball, S. J. (1994). Education Reform. A critical and post-structural approach. Buckingham: Open University Press.

Ball, S. J. (2017). The Education Debate. Bristol: Policy Press.

Briscoe, D.R., Schuler, R.S., and Claus, L. (2009). International Human Resource Management: Policies and Practices for Multinational Enterprises. London: Routledge DES. (2006). Language Education Policy Profile Country Report: Ireland. Dublin: Department of Education and Skill/Council of Europe.

DES (2016). Action Plan for Education 2016- 2019. Available at: https://www.education.ie/en/Publications/Corporate-Reports/Strategy-

Statement/Department-of-Education-and-Skills-Strategy-Statement-2016-2019.pdf [Accessed 03 April 2019].

DES (2017a). Languages Connect. Ireland's Strategy for Foreign Languages in Education 2017-2026. Available at:

https://www.education.ie/en/Schools-Colleges/Information/Curriculum-and-

Syllabus/Foreign-Languages-Strategy/fls_languages_connect_strategy.pdf [Accessed 02 February 2019].

DES (2015a). The Framework for Junior Cycle. Available at: https://www.education.ie/en/Publications/Policy-Reports/Framework-for-JuniorCycle-2015.pdf [Accessed 03 April 2019].

DES (2015b). Specification for Junior Cycle Modern Foreign Languages. Available at: https://curriculumonline.ie/getmedia/bbb30195-a78a-4d66-9b80-

04af66349905/JCMFLspec.pdf [Accessed 03 April 2019].

DES (2015c). The Minister announces the publication of Framework for Junior Cycle 2015.

Available at: https://www.education.ie/en/Press-Events/Press-Releases/2015-PressReleases/PR2015-08-31.html [Accessed 03 April 2019].

DES. (2014). The National Strategy on Education for Sustainable Development in Ireland, 2014-2020. Available at:

https://www.education.ie/en/Publications/Education-Reports/National-Strategy-on-

Education-for-Sustainable-Development-in-Ireland-2014-2020.pdf [Accessed on 05 May 2019]. 
DES and Kildare Education Centre. (2012). Final Report on the Modern Languages in Primary School Initiative, 1998-2012. Available at: http://www.onevoiceforlanguages.com/uploads/2/4/6/7/24671559/mlpsi_final_report_ july_2012.pdf [Accessed on 13 February 2019].

European Commission (2015) Study on Foreign Language Proficiency and Employability Final Report. Available at:

https://op.europa.eu/en/publication-detail/-/publication/6e68f7e0-dd4a-11e6-ad7c01aa75ed71a1 [Accessed on 13 July 2019].

Fairclough, N. (2001). Language and Power (2nd edn). London: Longman.

Krzyżanowski, M. and Wodak, R. (2011). Political strategies and language policies: The European Union Lisbon Strategy and its implications for the EU's language and multilingual policy. Language Policy, 10: 115-136.

McNaboe, J., Condon, N., Milicevic, I., Hogan, A., and Wowczko, I. (2015) Vacancy Overview 2014. Skills and Labour Market Research Unit (SLMRU), SOLAS. Available at: https://www.education.ie/en/The-Department/BodiesandCommittees/EGFSN_Vacancy_Overview_2014.pdf [Accessed on 13 July 2019].

Little, D. (2003). Languages in the Post-Primary Curriculum: A Discussion Paper. Dublin: NCCA. Available at:

https://www.ncca.ie/media/1808/languages_in_the_postprimary_curriculum_a_discussion_pa per.pdf [Accessed 22 February 2019].

NCCA (2008). Modern Languages in the Primary School Curriculum: Feasibility and Futures. Available at:

https://www.ncca.ie/media/1876/mod_langs_in_psc_feasibility_and_futures_2008.pdf [Accessed 03 March 2019].

NCCA (2001). Modern Languages in Primary Schools. Teacher Guidelines. Available at: https://www.ncca.ie/media/1811/modern_languages_in_primary_schools_teacher_guidelines. pdf [Accessed 04 March 2019].

Post-Primary Languages Ireland (2018). PPLI Annual Report. Available at: https://www.paperturn-view.com/ppli/ppli-annual-report-2018?pid=NTA50294 [Accessed 04 March 2019].

Reisigl, M. and Wodak, R. (2009). The discourse-historical approach, in Wodak, R. and Meyer, M. (eds.) Methods of Critical Discourse Analysis (2nd edn, pp. 87-121). London: Sage Publications Ltd. 
Said, E. (1986). Foucault and the imagination of power, in Hoy, D. (ed.) Foucault: A Critical Reader (pp. 149-155). Oxford: Blackwell.

Schuller, T., Baron, S. and Field, J. (2000). Social capital: A review and critique, in Baron, S. et al. (eds.) Social Capital: Critical Perspectives (pp. 1-38). Oxford: Oxford University Press.

Sterling, S. (2008). Sustainable education - towards a deep learning response to unsustainability. Policy \& Practice: A Development Education Review, 6: 63-68.

Tapper, T. and Salter, B. (1978). Education and the Political Order. Salisbury: McMillan Press.

Van Dijk, T. (1993). Principles of critical discourse analysis. Discourse \& Society, 4(2): 249283.

Wodak, R. (2011). Critical linguistics and critical discourse analysis, in Zienkowski, J. et al. (eds.) Discursive pragmatics: A handbook of Pragmatics highlights (pp. 50-70). Amsterdam: John Benjamin Publishing Company.

Wodak, R. (2001). The Discourse-Historical Approach, in Wodak, R. and Meyer, M. (eds.) Methods of Critical Discourse Analysis (pp. 63-94). London: Sage.

Young, M. D. (1999). Multifocal education policy research: Toward a method for enhancing traditional education policy studies. American Educational Research Journal, 36: 677714.

\footnotetext{
${ }^{1}$ Department of Education and Science. The name and function of the department have evolved over the last decade. In May 2010 the current name i.e. Department of Education and Skills was adopted and has been in use ever since.

${ }^{2}$ Ireland operates a three-tier education system. Children as young as four years old can be enrolled at a primary level into either a national English-medium school or an Irish-medium school (Gaelscoil). The primary curriculum includes 11 compulsory subjects with English and Irish as the only languages taught at this level. Secondary education consists of a 3-year Junior Cycle followed by a 2-year or 3-year Senior Cycle depending on whether student avails of an optional gap year. The end of each Cycle is marked by a compulsory state exam in preparation for which up to 10 subjects can be taken. In terms of foreign language offering, depending on individual schools, demand and resources one or more languages (Italian, French, German, Spanish) are available to students in Junior Cycle. In Senior Cycle additional languages such as Arabic, Mandarin Chinese, Japanese, Polish, Portuguese, and Russian are introduced into the curriculum. The level of proficiency in any given language upon completion of secondary education is expected to be in the region of A2/B1 level of the Common European Framework of Reference for Languages (CEFR). Access to third-level education, and in particular to the university sector, can be gained without knowledge of any foreign language. However, four main colleges as part of their matriculation requirements expect applicants to have a third language (in addition to English and Irish) in order to be admitted to most of their degree programs.
} 